\title{
Sin meridianos y sin reloj: el mundo feliz de Alan Pauls
}

EMILIANO RODRÍGUEZ MONTIEL Universidad Nacional de Rosario - CONICET, Argentina

emiliano.r@conicet.gov.ar

\section{Resumen}

Este trabajo se propone explorar el conjunto de elementos formales y teóricos que conforman el espacio y el tiempo de la narrativa de Alan Pauls, a fin de comprender el mundo anacrónico y atópico que se ficcionaliza en su literatura. La hipótesis sostiene que el mundo anacrónico y atópico ficcionalizado se constituye como una figuración de su concepción de lectura y estatuto $a$ contratiempo de su política de escritura, así como de lo contemporáneo/pos-global, en tanto que permite dilucidar la insuficiencia conceptual de las nociones modernas de «tiempo histórico» y «mundo» para interpretar las experiencias literarias analizadas.

Palabras clave: anacronismo / no-mundo / lectura / contemporaneidad / felicidad

\section{Without meridians and without clock: Alan}

\section{Pauls's happy world}

Abstract

The aim of this paper is to explore and to analyze the set of formal and theoretical elements that makes up the space and the time Alan Pauls's narrative in order to understand the anachronistic and atopic world fictionalized there. My hypothesis is that anachronistic and atopic world fictionalized is established as a figuration of reading conception and statute to setback of his writing, as well as of contemporary/post-global, as it allows clarify conceptual inadequacy of modern notions of «historical time» and «world».

Key words: anachronism / no-worlding / reading / contemporaneity / happiness

Recibido: 15/11/2018. Aceptado: 13/03/2019

Para citar este artículo: Rodríguez Montiel, Emiliano (2019). Sin meridianos y sin reloj: el mundo feliz de Alan Pauls. El taco en la brea, 9 (diciembre-mayo), 19-33. Santa Fe, Argentina: UNL. DOI: 10.14409/tb. v1ig. 8185 
Podría suponerse, en la condición dispensada de la conjetura, que las formulaciones generales de este trabajo se encuentran abreviadas en una de las entradas de Trance (2018), el último ensayo de Alan Pauls:

zugzwang. Así llaman los alemanes, en ajedrez, a la situación crítica, al parecer indeseable, en que un jugador se encuentra en el mismo callejón sin salida que él en el avión: la obligación de mover. Solo que eso que el jugador toma por una crisis terminal, porque el movimiento al que está condenado lleva al desastre, él, en su asientito de avión, con el cinturón abrochadito y el rayo implacable de la lámpara de techo impactando en el centro de la página del libro que tiene abierto sobre los muslos, está en el paraíso. Lejos de ser un tormento, la cancelación de toda posibilidad se parece mucho a un milagro, en la medida en que realiza en la práctica, sin oposición, una utopía que ningún lector conquista sin dejar su sangre, su sudor y sus lágrimas en la pantalla. Está obligado a leer. Para el modesto masoquista que se acoge en él, chay acaso una sentencia más irresistible? (121)

Hay un conjunto de términos en este fragmento — «callejón sin salida», «obligación de mover», «crisis terminal», «desastre», «cancelación de toda posibilidad»— cuya asociación permite elucubrar una imagen a escala reducida del singular mundo que se ficcionaliza en la literatura de Alan Pauls: un mundo detenido y atópico, privado en simultáneo de la posibilidad de regirse bajo las convenciones del tiempo histórico, así como de cualquier horizonte de sentido suministrado por la inscripción en tal o cual espacio telúrico. El mundo figurado en las ficciones de Pauls está exento, en otras palabras, de los preceptos de la cronología y las filiaciones territoriales, del tiempo del reloj y del perímetro del mundo, sea este delimitado por el discurso particularista identitario o por el imaginario cosmopolita de la globalización. Pauls deroga las leyes que han regulado desde la modernidad la experiencia espacio-temporal de lo humano para erigir, sobre la superficie de lo narrado, una dimensión anacrónica sin domicilio cuya única oferta de vida posible supone el ostracismo, la ignorancia, la errancia y la procrastinación.

Tanto Wasabi (1994), El pasado (2003) y «Noche de Opwijk» (2013), las tres ficciones que esta lectura se propone incursionar, narran, en efecto, un mundo cuya cadencia espacio-temporal, a causa de un desplazamiento territorial del personaje, se descompone, se desquicia, estropeando todo aquello configurado según sus normas: la fuerza creadora, la identidad, las pertenencias, el tiempo del reloj y la geolocalización. Una vivencia de no-mundo que se experimenta, no obstante, tal y como rezan los términos «paraíso» y «milagro» de la cita inicial, de forma feliz. Si la pérdida de la organización espacio-temporal de la modernidad supone, al decir de Mariano Siskind, «the painful sensation of the loss of the World» (2018:6), ese mundo apátrida e intempestivo al que son arrojados los personajes paulsianos, lejos de ser vivenciado de forma angustiante y melancólica, es experimentado dichosamente. El devenir homeless les posibilita a estos personajes obtener el pasaporte de ingreso a un nuevo horizonte de habitabilidad, legislado ya no por la obligatoriedad del progreso sino por la zona franca de un mundo sin meridianos y sin reloj: un agujero negro espacio-temporal donde el sujeto instaura, al igual que Pauls con la lectura en la cita inicial, una experiencia de trance con el mundo. En otras palabras, el no-mundo ficcionalizado en la narrativa paulsiana es feliz porque figura la experiencia de la lectura, porque en las vidas procrastinadas de los personajes paulsianos se disponen las condiciones con las que el lector, frente al libro, cancela el mundo para establecer con él una relación de pura potencia vivificadora. 
Explorar los elementos formales y teóricos con los cuales Pauls construye esta dimensión espacio-temporal anacrónica y atópica, comprender, en otras palabras, la naturaleza estética y conceptual del particular mundo que se ficcionaliza en la literatura paulsiana, es el propósito de este trabajo. La hipótesis que conducirá las formulaciones del mismo - y que se desprende de la doble pregunta en torno a la significación de: a) abordar este problema dentro del estudio y análisis de la obra de Alan Pauls; y b) producir hoy desde la literatura un mundo configurado sin las coordenadas espacio-temporales de la modernidad - podría resumirse, en su mayor generalidad, así: el mundo anacrónico y atópico ficcionalizado en la narrativa paulsiana se constituye como una figuración de su concepción de lectura y estatuto a contratiempo de su política de escritura, así como de lo contemporáneo/pos-global, en tanto que permite dilucidar la insuficiencia conceptual de las nociones modernas de «tiempo histórico» $\mathrm{y}$ «mundo» para interpretar las experiencias literarias analizadas.

\section{Anacronismo y no-mundo}

En las discusiones actuales en torno a «lo contemporáneo» la transfiguración de las nociones modernas de tiempo y espacio ocupan un rol central. Desde diferentes vías de comprensión y análisis, puede apreciarse dentro de los estudios de la literatura y el arte latinoamericano una constante crítica con relación a la aparición de nuevas formas estéticas que ponen en crisis, esto dicho en su mayor generalidad, la configuración espacio-temporal del relato moderno. Dos de las categorías críticas operativizadas en esta coyuntura prolífica, proviniendo de diferentes rutas de problematización y portando sobre sí una diferente «edad teórica», son anacronismo (Rancière; Didi-Huberman 2000, 2002; Barthes; Agamben) y no-mundo (Siskind 2018). Estas nociones, que conforman el dispositivo de lectura a partir del cual este trabajo busca interpretar críticamente la narrativa paulsiana, resultan productivas en tanto que permiten apreciar la singularidad de la transfiguración espacio-temporal que se ficcionaliza en su obra. Se asigna como necesario, en este sentido, precisar tales conceptos.

El anacronismo es una dimensión de tiempos múltiples, cargada de dislocaciones e impasses, que suspende todo impulso eucrónico y propone un régimen temporal ya no uniforme y contiguo, sino diferido, etéreo e impuro. Esta categoría, considerada desde el siglo XV hasta mediados del siglo XX como un pecado en la medida en que su existencia desbarataba la lógica continuista de la disciplina positivista, es reconfigurada afirmativamente en las últimas décadas dentro del campo de estudios del arte y la literatura.' Por medio de una serie de teorizaciones significativas, en particular las de Jacques Rancière, Georges Didi-Huberman, Roland Barthes y Giorgio Agamben, se advierte un nuevo vigor teórico en la conceptualización y uso de la categoría. Porque, más allá de la singularidad de las búsquedas, alcances y coyunturas de cada proyecto teórico en particular, las intervenciones referidas conciertan en revisar la noción negativa del anacronismo —explícita o tácitamente y continuando la línea anti-historicista iniciada por Nietzsche y retomada por Benjamin - para reformularla productivamente según ciertos rasgos que, a la luz de sus reflexiones, se postulan como inherentes al concepto. A saber: el carácter reactivo, literario y contemporáneo del anacronismo. ${ }^{2}$

Reactivo, en primer término, por su doble propiedad de reacción y transformación. El anacronismo, en la consideración de Didi-Huberman, se constituye tanto como una práctica de resistencia al régimen positivista de la modernidad, como una fuerza de mutación epistemológica 
capaz de posibilitar un nuevo modelo y uso del tiempo en el campo de las artes y la literatura. En concreto, Didi-Huberman cuestiona la tesis panofskiana de la historia del arte como disciplina humanista y su fuerte rechazo al anacronismo como procedimiento del historiador (36). Para Panofsky — siguiendo el precepto de Febvre — el historiador no debe cometer el pecado o herejía de proyectar su propio presente en el análisis del objeto, sino hallar una fuente de época que le permita interpretarlo «con veracidad» según una lógica causal. «Esta actitud canónica del historiador no es otra cosa que una búsqueda de concordancia de los tiempos, una búsqueda de la concordancia eucrónica» (36). Frente a esto, el teórico francés plantea la necesidad de pensar una nueva historia del arte capaz de abandonar el eucronismo panofskiano para interrogarse sobre «los diferenciales de tiempo que operan en cada imagen» (40). Ante el punto de vista convencional de «el artista y su tiempo», Didi-Huberman antepone «el artista contra su tiempo». ${ }^{3}$

Literario, en segundo término, por definir, antes que los deberes del historiador, los derechos y el estatuto de la ficción. Rancière retoma lo dicho por Febvre y se interroga por el motivo fundamental que impulsa al positivismo histórico a considerar el anacronismo como un pecado. Su hipótesis, reveladora, sostiene que en el fondo del problema, el anacronismo no es considerado una falta por atentar contra la sucesión de los tiempos sino por quebrantar una operación vertical de similitud y empalme entre el tiempo histórico y un tiempo sin datación, «soit ce que l’on appelle ordinairement l'éternité» (54). El tiempo humano, su ordenamiento horizontal por épocas, funciona, según Rancière (57), como sustituto de la eternidad. Cada época comporta sobre sí un régimen de verdad particular, una totalidad significante o relato verosímilmente articulado que substituye verticalmente un tiempo sin tiempo: «Le temps est l'image mobile de l'éternité immobile» (55). La historia, de este modo, para constituirse como ciencia, disipa la distinción que mantiene con la narración (History y story) y funda para sí una verdad sirviéndose de los tres procedimientos tradicionales de esta última: «l'inventio, la dispositio et l'elocutio» (53). El establecimiento de la historia como discurso verdadero depende, entonces, por su capacidad de poder tornarse semejante a la literatura, «d'imiter pour son compte la puissance de généralité poétique» (56). Y es por eso, señala Rancière, que el anacronismo es concebido como un pecado: por precipitarse contra la lógica verosímil que resulta del pacto entre literatura e historia, entre narración y semantización de los hechos. Ahora bien, y es aquí donde Rancière subraya la paradoja: tal operación de empalme entre un tiempo humano y un tiempo «legendario» pertenece originariamente a la ficción, constatándose ejemplarmente en la historia amorosa entre Eneas (tiempo histórico: la fundación de Cártago) y Dido (tiempo ficcional: la Guerra de Troya). En este sentido, sostiene Rancière, el anacronismo concierne a la verdad de la literatura antes que a la verdad de la historia: «l'anachronisme est un concept poétique que tient lieu de réglement philosophique de la question portant sur le statut de vérité du discurs historien» (53). La historia, en otras palabras, se constituye como ciencia resolviendo teóricamente su estatuto de verdad a través de un procedimiento literario que ella misma sentencia como pecado: el anacronismo. ${ }^{4}$

Contemporáneo, en último término, por la paradojal experiencia intempestiva que instaura con el presente. El anacronismo se alza como una vivencia desfasada, inactual, en el centro del tiempo histórico que permite, por un lado, forjar una relación esencial, «verdadera», entre el hombre y su tiempo (Agamben:8); y por otro, poner en escena «una fantasía de concomitancia», esto es, la convivencia sobre una misma superficie (la escritura) de dos o más temporalidades - literarias, teóricas - separadas cronológicamente (Barthes:48). Para Agamben el problema de la 
contemporaneidad es una cuestión de posición, para Barthes un asunto de contigüidad y correspondencia. Por situarse no en el fulgor de la actualidad ni en la nostalgia del pasado sino en el «umbral inasible entre un "no todavía" y un "ya no"» (25), el anacronismo, para Agamben, brinda la distancia necesaria para poder relacionarse fecundamente con su tiempo, sin cegarse con las «luces» del presente, ni quedarse detenido contemplando los fósiles de lo ya muerto. Por su parte, en la presentación del seminario Cómo vivirjuntos de 1977, Barthes se interroga por los autores con los que su pensamiento, y en especial los vinculantes al seminario (Marx, Freud, Nietzsche, Mallarmé), entra en conversación («¿De quién soy contemporáneo? ¿Con quién estoy viviendo?» —48一), advirtiendo que no es en el «juego cronológico» donde puede hallar una respuesta satisfactoria, sino en el orden «insospechado» de lo intempestivo. De esta manera el anacronismo se concibe como una fuerza que posibilita una relación fantasmática, de montaje, con el propio tiempo. ${ }^{5}$

Ahora bien, si el anacronismo goza de legitimidad en la escena teórica actual a causa del renovado potencial o "giro afirmativo» elucubrado en las reconceptualizaciones referidas, la categoría de no-mundo (unworlding) de Mariano Siskind surge, en cambio, por el devenir estéril de otra noción del mismo autor: «mundo». En efecto, Siskind postula que la categoría de «mundo», aquella totalidad discursiva universal constituida sobre la base particular de los derechos y normas morales burgueses (la «Weltrepublik» kantiana), fructuosa para leer los «deseos cosmopolitas» o deseos de mundo del modernismo latinoamericano, resulta inhábil para interpretar el sentido general de pérdida que define la coyuntura histórica actual (Siskind 2016:47; 2018:7). Los desplazamientos forzados de migrantes y refugiados, la ausencia de hospitalidad de los estado-nación, la profundización en la desigualdad socioeconómica entre países del primer y tercer mundo, la guerra sostenida en Medio Oriente, la disipación de las fronteras geopolíticas y la experiencia generalizada de destitución, dislocación y no-pertenencia que esto ocasiona, la alarmante desnutrición infantil, la acentuación de la xenofobia, el racismo sexual, cultural e institucional, entre otras prácticas de intolerancia y políticas de desprotección deliberadas (jurídicas, sanitarias, educativas, etc.), producen, para Siskind, «the painful sensation of the loss of the World» (2018:6). El mundo que imaginó el proyecto filosófico de la modernidad y que se narrativizó en la novela del Siglo XIX (Siskind se detiene en las novelas de Julio Verne), un mundo «ocupable», «viajable», «emancipado», «humanista», «conectado», «receptivo» y por ello «deseable» por los cosmopolitas marginales latinoamericanos, es un mundo que ya no existe (2016:64-72, 151-240). El acuciante presente forma, por el contrario, un sujeto cuyo periplo ya no apunta a ningún tipo de conquista sobre el mundo (modernidad global "goce cosmopolita» utopía de mundo) sino a la imposibilidad traumática de habitarlo (contemporaneidad «sensación de pérdida» atopía de mundo). Sin un mundo donde poder afincarse, regulado por «the idea of the end of the world» (2018:14), el sujeto de no-mundo forja su experiencia alrededor de la errancia y de la pérdida, una forma homeless que Siskind reconoce traducida, en tanto figuración estética, en la narrativa latinoamericana contemporánea:

I am thinking of narratives by Roberto Bolaño, João Gilberto Noll, César Aira, Chico Buarque, Guadalupe Nettel, Mario Bellatin, Lina Meruane, Sergio Chejfec, Eduardo Halfon, Irmgard Emmelhainz, Mike Wilson, Yuri Herrera, Verónica Gerber Bicecci, Edgardo Cozarinsky, and perhaps only a few others that I may not know of (...). Regardless of their plots, and their characters and non-characters, regardless of whether they narrate a wide variety of forced and traumatic displacements (...), the formal features of these narratives haunt the worldliness of the world. They shake up the structures that once sustained the fiction of the 
world as a totality of modern/modernist meaning, and the politically effective fantasy of universal inclusion implied in the obsolete notion of world-citizenship. (2018:20)

Sin las coordenadas espacio-temporales estructurantes de la modernidad, ciertas producciones de la literatura latinoamericana producen hoy un mundo en el que "no se puede hacer pie» (2018:7). ${ }^{6}$ Un mundo sin meridianos y sin reloj, de pura pérdida y errancia, que los personajes paulsianos habitan, no obstante, de forma feliz, a contrapelo del pronóstico desgarrador generado por la idea de «Fin de mundo». Comprender las razones de esta dicha, dar cuenta de hasta qué punto esta felicidad paulsiana se explica por habitar un mundo cuyo tiempo y espacio se corresponde al de la lectura, y por extensión, al de la literatura, es tarea del siguiente apartado.

\section{Del ethos telúrico al pathos del no-mundo}

$\mathrm{Al}$ explorar el atlas de la narrativa paulsiana se advierte que tanto en Wasabi (1994), «Noche de Opwijk» (2013) y El pasado (2003) se narra un mismo tipo de viaje, semejante no sólo por la análoga invitación laboral que impulsa el desplazamiento, sino por el particular modo en que se narra el tiempo y el espacio. Hay un tiempo en estos tres relatos que es ficcionalizado según formas propias del régimen temporal del anacronismo, a saber: la epifanía, la catalepsia y el jet lag. Hay, a su vez, un conjunto de características espaciales que permiten pensar en la conformación de una serie topográfica de no-mundo. Comenzando por esto último, se constata que, como si la narrativa paulsiana fuera, antes que otra cosa, un espectáculo ambulante que tuviera que trasladar y montar, de ficción en ficción, un mismo escenario telúrico precarizado, los tres viajes paulsianos se sitúan en espacios suburbanos gobernados por el desamparo, la hostilidad y la miseria. La ruta de viaje es, más allá de los matices propios de cada texto, la misma: se parte siempre desde un sitio acondicionado para ser deseable (ocupable, conectado, conocido, del mundo) y se llega a un destino invivible, al que se lo ha puesto fuera de lugar. Un espacio estetizado atópicamente que recrea, por estar materializado bajo el signo del olvido y cierto tono lúgubre, por estar regulado según una lógica atmosférica que no contempla más que el tedio y la precariedad generalizada del ambiente, la idea de pérdida del mundo, de ese mundo habitable del cual se partió. Cabe subrayar, no obstante, que los viajes paulsianos no replican los trayectos que invierten el viaje modernista del cosmopolita marginal latinoamericano, esto son, los desplazamientos que van del centro a la periferia (sea por el motivo que fuera: conquista, exotismo, turismo, explotación, etc.), sino que instituyen, sobre la superficie de la escritura, un proceso de marginalización material y experiencial del espacio al que se arriba, se trate de un espacio geopolíticamente fronterizo o de una ciudad capital donde reside y se administra el poder. Esto se advierte con más perspicacia al constatar el subterráneo París que se ficcionaliza en Wasabi o el ignoto San Pablo que se narra en El pasado. El periplo puede consistir, si, en el traspaso de una capital a una localidad pequeña lindante (Bruselas > Opwijk), pero también puede ocurrir a la inversa (París > Saint-Nazaire) o, mejor aún, sobre un mismo espacio (del Hotel a la Feria del libro en San Pablo). Se trata, en otras palabras, de una transformación del orden escénico-vivencial del territorio, del paso del ethos telúrico al pathos del no-mundo. Se cita a continuación, a modo ilustrativo, una descripción de estos no-lugares paulsianos, en el siguiente orden: Saint-Nazaire (Wasabi), la Feria del Libro de San Pablo (El pasado) y Opwijk en «Noche de Opwijk»: 
Atravesamos el puerto bajo la luz opaca de la tarde. Todo estaba desierto (...) ¿Quién seguía a quién en ese vagabundeo de mendigos? (1994:36); La soledad, el clima hostil (...) yo ya no deseaba, no temía, no esperaba nada (74); vagabundeaba como un sonámbulo por las calles de un barrio desconocido. (141)

Se arrepintió cuando después de bajar, feliz por el simple hecho de haber llegado, salió por fin a la calle y un cielo blanco lo encegueció, y un perfume de frituras y pescado rancio revoloteó a su alrededor, y el paisaje en el que había planeado pasar las próximas horas de su vida terminó de definirse ante sus ojos: avenida desierta, perros, estación de servicio, autos abandonados, casas pobres y bajas, talleres mecánicos, terrenos baldíos cargados de chatarra. Y en el fondo, temblando en una nube de vapor y gasolina, los dos inmensos galpones a los que la municipalidad de San Pablo había decidido mudar la Feria del Libro (...) Qué error, pensó Rímini. (2003:242-244)

Eran las cuatro menos veinte de la tarde, el lugar estaba desierto, la mitad de los negocios cerrados (2013:2); Imposible distinguir el día de la noche. Esta vez, para colmo, no había un alma, literalmente (2); ¿Quién diablos lo manda a perderse un viernes en ese páramo que para colmo ni siquiera es francófono? Se deja arrastrar por unos racimos de jóvenes que parecen saber adónde van. Usan buzos con capucha, beben cerveza. En un momento, uno que lleva un skate bajo el brazo se vuelve, le arroja una mirada de rencor y da una pitada furibunda a su cigarrillo, pero no dice nada. Caminan por la calle principal, prácticamente a oscuras. Unos pocos negocios cerrados los vigilan desde la sombra. Alguien los cruza en bicicleta (...) El concierto es en el tinglado principal, un espacio frío y hostil, con algo de patio techado de cárcel. (3)

Por lo demás, la sensación de pérdida figurada en estos no-mundos se ve potenciada en el conjunto de cosas que los personajes pierden, ellos mismos incluidos, a lo largo de la narración; a saber: la fuerza creadora, la identidad, las pertenencias, el tiempo del reloj y la geolocalización. La «pérdida» en tanto narración de algo que se tiene y que se pierde en el transcurso de la historia, o de algo que está perdido de antemano y que se quiere recuperar, es una figura recurrente en la narrativa paulsiana, un tópico que orquesta, en la mayoría de sus novelas, la economía del relato. Sea un saber, un objeto del mundo o simplemente una sensación, los personajes paulsianos, en tanto agentes de la pérdida, caen, tarde o temprano, en un foso orbitado por el ostracismo, la ignorancia, la errancia y la procrastinación. ${ }^{7}$

Wasabi y «Noche de Opwijk» narran, en concreto, la misma historia: un escritor es invitado a pasar una estadía corta en el extranjero (dos meses en Saint-Nazaire en Wasabi, un mes en Bruselas en «Noche de Opwijk») a cambio de que testimonie brevemente, por escrito, su experiencia en la ciudad. Este contrato o forma de pago se torna irrealizable una vez allí, dado que la escritura, el impulso inventivo de su praxis, se pierde. En El pasado, por su parte, Rímini pierde su capacidad para traducir antes de su viaje a San Pablo: «Lo perdía todo. Iba perdiéndolo por partes, sin orden y sin lógica. Una tarde podía perder toda la conjugación del francés, y a los dos o tres días el sistema de acentos, y una semana más tarde el significado de la palabra blotti (...) Era como un cáncer» (2003:234). Sea como fuere, voluntaria ( (Noche de Opwijk»), involuntaria (Wasabi), o de antemano (El pasado), el no escribir para estos escritores supone, y de diversos modos, otra pérdida: la de la identidad. En Wasabi la imposibilidad de escribir implica el devenir-monstruo de su protagonista. Wasabi es el relato de cómo Pauls pervierte una vivencia personal por medio de una operación abyecta en donde el yo encargado de pronunciarse por él se desdobla, siendo despojado de todo elemento de la cultura. ${ }^{8}$ 
Golpeado por el portero de la casa donde vive Klossowski, asaltado por unos irlandeses que le roban todas sus pertenencias, vagabundo por más de una semana en París y aquejado por un quiste que no para de crecer sobre su nuca, el álter ego paulsiano pierde su figura antrópica y se convierte en un ser teriomorfo. El quiste, esa cavidad con forma de púa, esa «carne reducida a un estado de máxima pureza, pura carne cruda» (1994:31), toma el lugar que su dueño deja en el mundo y paga la deuda contraída por él a través de una instanciación monstruosa: «¿Era el transcurso de los días lo que yo padecía, o más bien el privilegio de ser contemporáneo de mi propia degradación, el testigo de las evidencias que con el correr de las horas iban apartándome de lo humano?» (82). Sumergido en la dimensión de lo impersonal, en el tartamudeo o murmullo de lo anónimo — «ya no podía casi mirar a la gente a la cara; sin embargo veía mi reflejo atroz en la cortesía con que se hacían a un lado para dejarme pasar» (72)—, ahora, dice Laera, es un homeless: «En París ya no hay deambular, ya no hay contemplación estetizante, ya no hay registro urbano: sólo vagabundeo y extrañamiento de sí mismo» (2009:467). El alter-ego paulsiano alcanza el anonimato absoluto, el grado cero identitario, al final de la novela, cuando su editor lo confunde con un impostor: «Es la primera vez en mi vida que lo veo: pretende hacerse pasar por un autor de mi editorial» (138).

La idea de impostura, al igual que la de pérdida, ocupa un lugar privilegiado en la narrativa paulsiana. Su literatura está llena de profesionales de la doble vida: intrusos, enmascarados, estafadores, espías, farsantes, usurpadores. Es un perfil propio de gag del que Rímini (El pasado) y el ex-escritor de Opwijk, al igual que el monstruo de Wasabi, no son la excepción sino que forman parte, enteramente y sin variación, de este voluminoso grupo gravitado alrededor del fracaso, la mediocridad y la ilegalidad. ${ }^{9}$ Para poder ingresar y usufructuar los servicios del congreso al que asiste en calidad de acompañante, Rímini debe usar la credencial de un tal Idelber Avelar, un traductor de Puerto Alegre cuya ausencia no sólo le permite entrar, circular y almorzar, el lado A del asunto, sino que lo obliga, por estar ceñido a convivir públicamente horas y horas ante un otro desconocido, al enroque de nacionalidades, de lenguas y de nombres..$^{10} \mathrm{El}$ ex-escritor de Opwijk, por su parte, da vuelta su vida «como un guante»: abandona su profesión literaria y se convierte en DJ, renuncia a su condición de argentino y se nacionaliza alemán. Todo esto sin que la institución cultural que lo invita a una residencia de escritores en Bruselas lo sepa. Por eso, al igual que un performer, una vez en suelo extranjero, actúa la identidad abandonada."

De cualquier modo, si al igual que el monstruo paulsiano ninguno de estos impostores la pasa bien en tierra foránea — Rímini, entre la «náusea y el vértigo» (2003:244) termina llorando, arrasado por el dolor y «la cara hundida entre las manos» (2013:251), el DJ, por su lado, acaba «sentado en el piso, en el mismo rincón, con la botella de cerveza vacía entre las piernas, la gente lo pisa, lo golpea, se lo lleva por delante, volcándole encima vodka, agua, esas pegajosas bebidas energizantes» (4)-, no se debe sólo por su nueva condición de errabundos y falsarios, sino por la forma en que tales personajes vivencian el tiempo. Un tiempo que, ensamblado pieza por pieza con la coordenada espacial, al punto de dificultar cualquier intento de pensarlos por separado, figura descompuesto, revuelto, inmune a la continuidad cronológica. Es un tiempo hiato (Pauls 2018:43) que deroga el presente a través de la puesta en marcha de un tríptico anacrónico, especie de arsenal anti-historicista confeccionado para boicotear la progresión del tiempo, a saber: la catalepsia, la epifanía y el jet lag. El monstruo paulsiano de Wasabi es aquejado episódicamente por ataques catalépticos, los cuales, en tanto «cortocircuitos, chispazos de ausencia» (17), lo ausentan del mundo por siete minutos. Esta parcela de vida que se pierde significa la entrada a una vida límbica, incapaz de resincronizarse 
con el mundo sin eludir el filtro de alguna de las innumerables formas que adquiere la prórroga: la impuntualidad, el desconcierto, la ignorancia, la somnolencia, la apariencia del mundo como déjà $v u$, es decir, como fotocopia, artificio o montaje de algo ya vivido (20). Rímini, por su lado, prisionero de la mujer-monstruo, es bombardeado intermitentemente por revelaciones epifánicas, las cuales, a contracorriente de los bálsamos vitales proustianos — novela con la que El pasado entra en conversación-, aquellos destellos del pasado amoroso son para Rímini cuchillas, infalibles lanzas incisivas que penetran por entero todo su ser. ${ }^{12}$ La novela narra un total de cinco epifanías, siendo una de ellas la que acontece en la Feria del Libro de San Pablo, cuando Rímini reconoce en la contratapa de un libro el rostro de Caique de Sousa Dantas, un actor portugués, amigo y sospechado amante de Sofía: «Rímini lloró, lloró, lloró, hasta que los ojos le ardieron tanto que no tuvo más remedio que dormirse» (254). Sumido en el impasse de un presente infectado por el desentierro involuntario del pasado, Rímini lo pierde todo, poco a poco, convirtiéndose en una obra maestra de la inercia, sin dirección ni propósito: vida inmanente, vida en caída libre. El DJ de Opwijk, por último, sufre los efectos devastadores de lo que, al decir de Érica Durante, se instituye como «un fenómeno consustancial de nuestra condición de residentes del planeta» (2015:101): el jet lag. Este incidente temporal, producido por el desajuste entre el reloj del mundo y el reloj del cuerpo, favorece el nacimiento de una experiencia «flotante, ambigua, in-between» (109), que explica no sólo la condición nómada del héroe paulsiano («En algún momento la residencia terminaría y tendría que volver. Pero ¿a qué? ¿Volver adónde?» - Pauls 2013:2-), sus sueños, su confusión en las referencias temporales («Pierde la capacidad para calcular el tiempo»; «imposible distinguir el día de la noche» -3-) sino, sobre todo, su desdoblamiento identitario. El héroe paulsiano aprovecha la vida stand by que le propone el jet lag para dar rienda suelta a toda una vida puesta en reserva, ahorrada, contenida incógnitamente en la sincronía de la vida anterior. No obstante, el tiempo ofrecido en esta dimensión, la libertad que ésta promete, tal y como lo demuestran cada uno de los infortunios narrados, es una trampa. Por ser un tiempo gestado en un no-lugar por excelencia, el avión —espacio paradójico que combina el colmo de la celeridad, el viaje aéreo, con el colmo del estatismo, la cárcel—, el DJ de Opwijk no tiene a dónde ir. La convalecencia espacio-temporal de ese espacio suburbano se comprende, en definitiva, como una imagen razonada, réplica o proyección de aquel espacio contorneado en el aire.

\section{La felicidad de la lectura}

La privación: piedra de toque del goce de leer.

Aprende la lección —aunque tal vez

ya la hubiera aprendido antes, de chico, gracias

a esos ejercicios privados a los que

se la da por entregarse en pleno trance lector,

cuando hace de cuenta que el mundo

ha desaparecido con todo adentro,

incluido todo lo que él ama menos lo que lee, y de pronto,

solo en medio de la nada, porque ni ruinas ha dejado la catástrofe,

se ve a sí mismo con su libro

y se dice muy suavemente (...): «Soy feliz».

Pauls 2018:3 
Ahora bien, es en este mundo deshecho, cancelado, sin meridianos ni reloj, donde se advierte, a contrapelo del pronóstico desgarrador generado por la idea de "Fin de mundo», un insospechado estado de dicha en los personajes paulsianos. Puede significar un momento, un instante, lo que dura el trazado de un relámpago en el cielo. Poco importa: por más efímero que se manifieste, se germina en el centro del mundo que se pierde un abrigo anímico, la promesa de un nuevo horizonte de habitabilidad, de un nuevo espacio ocupable, un sentimiento profiláctico a todas luces desubicado, que contrasta insolentemente, como un rayo de sol en el medio de una tormenta, con el mundo que se desmorona frente a sus ojos. No es una cuestión de eficacia, de obtención de resultados, de retorno, si se quiere, al ethos telúrico vivido. Se trata, más bien, del advenimiento, en el corazón del pathos del no-mundo, de una fuerza, una energía, una potencia:

\footnotetext{
Y sin embargo algo se puso a destellar en la crudeza de esa pesadilla, algo que irrumpió como una revelación pero que era apenas un recuerdo (...): Saint-Nazaire (...) Lo que brillaba era la existencia del recuerdo, no su contenido: la prueba de que ese infierno, homogéneo y liso como se me presentaba, todavía podía resquebrajarse. De pronto Saint-Nazaire fue mi patria, mi infancia, la sede de una vida invalorable y prematura que había perdido para siempre y que sin embargo ninguna catástrofe, ni siquiera la que se había abatido sobre mí, reduciéndome a la pura contemplación de mi fin, podía borrar jamás. (1994:84)
}

Se quedó en la cola un rato, y mientras la veía crecer a un ritmo asombroso, se sintió reconfortado por un extraño bienestar, como si, a pesar de todo, el contacto con esa multitud de desconocidos le proporcionara alguna forma de calor y amparo (...) Llovía — una de esas tormentas que anuncian de golpe el fin del mundo-, pero el estrépito lo había reanimado (...), y sintió una pesadez muy agradable en los pies. (2003:245-246)

Fue una especie de rapto: como entrar en otro mundo (...) Nunca se había visto tan feliz. Sentía el bienestar maduro y cansado que siente una piedra que se ha quedado quieta, por fin, después de rodar días y días a la intemperie (...) con qué buen humor, con qué ímpetu eufórico había franqueado la entrada. (2013:2-3)

Hay en los viajes paulsianos una vida que se diluye con la invalidez creativa y la identidad cívico-laboral, un mundo conocido con sus redes, tiempos y sentidos, un mundo fértil, impulsado hacia delante, hermanado a la escritura, la literatura y a la vida útil de ciertos saberes telúricos. Pero también hay, en este juego de balance, la ganancia de una posibilidad de vida desconocida. Dicho de otro modo, en el meollo de la vivencia de «Fin de mundo» se erige una zona franca de habitabilidad, un oasis acondicionado para el devenir feliz de quién caiga allí, errabundo, luego de perderlo todo. Por ello, para ganar el mundo, hay que primero perderlo: perder la palabra, la lengua, el nombre, el tiempo y el espacio. No hay tregua sin cancelación telúrica, no hay dicha sin divorcio entre el sujeto y el mundo, no hay felicidad, en último término, sin reacción y transformación. Por eso, este proceso reactivo no debe comprenderse como un simple acto de escapismo sino como uno semejante, tal es la hipótesis que se ensaya, al que sucede en la lectura: exenta de todo fin utilitario, inmune a todo compromiso con la vida, dedicada a estar fuera de lugary a cultivar con empeño la procrastinación, se produce en el acto de leer «un vivir intenso, vertiginoso, sin vueltas atrás, al que ninguna acción permitirá acceder jamás» (Pauls 2018:26). El mundo anacrónico y atópico paulsiano figura, en este sentido, la experiencia feliz que se forja entre libro y lector. El 
intempestivo estado de éxtasis en el que entran los personajes paulsianos ficcionaliza, en otras palabras, la conceptualización de lectura que Pauls teoriza, entre otros ensayos, en Trance. ${ }^{13} \mathrm{El}$ término «trance» proviene del latín transīre, que significa transitar, transportarse, cruzar, «entrar en». La lectura, de esta forma, es una experiencia dinámica, de trance, porque sobre se ella —sobre «la asincronía fundamental» (29) que se establece entre lector y libro, esa superficie extemporánea, incongruente, de «hiato» en el que se ejecuta el acto de leer- se posibilita el ingreso a otra extensión habitable, vivible. La relación de la lectura con la vida no sería, por lo dicho, «de oposición, ni de exclusión, ni de enseñanza, ni de complementariedad, sino pura y simplemente» (27) de felicidad: la lectura es un juego de interpretación, de desplazamiento, de agregar, en el torrente de la imaginación razonada, «mundos al mundo» (20).

La felicidad de la lectura es tal que Pauls trasladará a su escritura aquello que la define: el estatuto a contratiempo. En efecto, de esto se trata, ante todo, en la literatura de Alan Pauls: de la construcción estética de una dimensión desincronizada, inmune al tiempo cronológico, de la postulación de un espacio-madriguera domiciliado en el piso subterráneo de la diacronía del mundo. Si el anacronismo es, al decir de Rancière, el tiempo original de lo literario, y si el anacronismo es la condición sine qua non de la lectura, será justamente esta fuerza de la que Pauls no querrá desprenderse al pasar de la lectura a la escritura:

Descubre muy temprano que nada le importa más que leer. Lee todo lo que puede, lo que encuentra. Lee hasta lo que no entiende. Poco a poco (...) su comportamiento (...) se vuelve demasiado visible. Los demás, misteriosamente, se sienten llamados a intervenir (...) Irrumpen en su habitación, le hablan en voz alta, le recuerdan todo lo incalculablemente valioso que olvida, que posterga, que reemplaza por estar ahí tirado con sus libritos. Le exigen que haga algo. Él, en el único rapto de inspiración que tendrá en su vida, decide ser escritor. Los escritores leen, piensa. Les da lo que quieren (un hacer) para quedarse él, en secreto, invulnerable, con lo que él quiere: un gozar. (2018:7)

El anacronismo del no-mundo paulsiano no sólo ficcionaliza, en este sentido, la condición de lectura paulsiana sino, especialmente, el estatuto a contratiempo a partir del cual Pauls pone en marcha su máquina literaria. Esto se vuelve más que evidente en la "fantasía de concomitancia» (Barthes) a partir del cual Pauls, a nivel formal y referencial, construye su narrativa. En primer lugar, Pauls sintetiza — como un ecualizador que ajusta, arregla e integra sonidos irreconciliables - tradiciones, estilos y materias disímiles (el «buen» y el «mal» gusto, lo géneros menores —el policial y el epistolar — con la literatura «alta», lo nacional — Borges, Puig, Saer y Piglia, entre otros-y lo extranjero - Kafka, Proust, Bataille y Klossowski, entre otros—, la estética negativa del alto-modernismo con el kitsch) en su proceso creativo. Este sistema de correspondencias se despliega sobre una temporalidad no progresiva ni recta sino anacrónica, posibilitando que poéticas incompatibles estética y temporalmente armonicen en una misma superficie de escritura. Para el Pauls escritor, y sobre todo para el Pauls lector, el anacronismo es un dispositivo de interpretación insubordinado que le permite posicionarse con absoluta libertad frente al objeto literario. Producir literatura según la política del tiempo del anacronismo consiste en practicar, en este sentido, una insolencia positiva hacia la tradición, una deliberada y fecunda irreverencia hacia sus prescripciones y prerrogativas, hacia sus antagonismos organizados y clasificaciones periódicas paternalistas afijadas con pre y post. Una operación, en suma, de desajuste y suspensión del 
tiempo de la lengua, de negación de sus sincronismos y diacronismos estructurantes. En segundo lugar, a nivel formal, la frase paulsiana es una complejidad sintáctica que se despliega en una extensión espiralada y condensa, bajo un procedimiento por incruste, una multiplicidad de imágenes, enumeraciones, comparaciones y mini-relatos, todos subordinados al enunciado original. Es una forma concéntrica que inicia - supongamos - en A y termina en $\mathrm{C}$, pero que entre medio se implanta $\mathrm{B}$, un $\mathrm{B}$ que comienza a ramificarse en $\mathrm{B}^{1}, \mathrm{~B}^{2}, \mathrm{~B}^{3} \mathrm{y}$ así sucesivamente hasta que todos los niveles argumentativos hayan sido exprimidos y puedan volver — después de «hacer tiempo» (Avaro:152) - a C. Esta condición parentética, que hace que la frase crezca por el medio — por inserción de cláusulas subordinadas—, se construye sobre la base de una convivencia extemporánea: la de Juan José Saer y Marcel Proust. ${ }^{14}$

Así pues, es en el tiempo sin tiempo de la literatura, en lo inclasificable de lo telúrico, cuando los fantasmas empiezan a rondar, el momento en que el mundo, más que un escenario posapocalíptico donde se vivencian las infinitas formas del desastre, deviene utopía.

\section{Notas}

1 La larga tradición de rechazo hacia el anacronismo comienza, siguiendo a François Dosse, en el siglo XV, «cuando los humanistas sientan las bases de un método crítico de las fuentes, decisivo en el vuelco de la noción de verdad» (58). El acontecimiento que le otorga cauce a este punto de inflexión metodológico data de 1440, cuando el humanista Lorenzo Valla establece que la Donación de Constantino es apócrifa. Por medio de un estudio filológico, Valla «hace un inventario de los múltiples errores lingüísticos, de los "barbarismos" del falsificador y de los múltiples anacronismos históricos» (59) del documento papal, dictaminando, por ello, el carácter falso del texto sagrado. Las incongruencias temporales detectadas son estimadas, como se describe, negativamente: la presencia del anacronismo revela el fraude. Este trabajo de investigación significaría el primer antecedente de un nuevo horizonte en el campo de la crítica histórica. Al perder los textos eclesiásticos su beata inmunidad y quedar, por ello, desprotegidos ante el escrutinio público, al nivelarse en derechos, en otras palabras, todos los textos ante la mirada del historiador, se habilita en la praxis histórica el desarrollo de un nuevo modo de hacer historia, codificado según criterios estrictos de verdad. Denominada «Historia anticuaria», esta nueva disciplina de lo verdadero configurada según los regímenes del tiempo cronológico, eclosiona, en efecto, en el siglo VII con la publicación de De re Diplomática de Jean Mabillon (1681). Apoyado en la erudición y los ritos disciplinares de la pesquisa documental maurista, Mabillon funda los principios metodológicos de la crítica docu- mental estableciendo el carácter fidedigno de ciertas cartas merovingias de la abadía de Saint Denis. El anacronismo continúa, en este marco, considerándose la anomalía a encontrarse en el rastrillaje historiográfico. Es, no obstante, en el Siglo XIX, «el siglo de la Historia» (229), con la profesionalización de la disciplina y el abrigo positivista al juicio científico, donde la categoría halla su mayor rechazo. Es el momento en que Historia y Literatura se separan. Para alcanzar autonomía y/o especificidad en el ámbito universitario, la disciplina histórica — su praxis de escritura - debe desembarazarse de toda huella estética, de toda figura retórica y/o búsqueda autoral de embellecer formalmente la prosa. La historia, en otras palabras, queriéndose científica, anónima, específica y pedagógica, se dedica a estar exenta de «los microbios literarios que contaminan el discurso histórico erudito» (60). La frase ya célebre de Lucien Febvre en su ensayo sobre Rabelais, punto de partida común de la teoría y crítica contemporánea para referirse al uso negativo del anacronismo (Loraux, Rancière, Didi-Huberman, Dosse), condensa ejemplarmente el modo en que el positivismo histórico, cristalizado en la Escuela de los Annales, concibió al anacronismo: «el problema consiste en (...) evitar el pecado mayor de todos los pecados, el más irremisible de todos: el anacronismo» (4).

2 Para un desarrollo pormenorizado de las formulaciones de Nietzsche y Benjamin en torno a la consideración afirmativa del anacronismo como «potencia no-histórica» y «fuerza mesiánica» respectivamente, ver: Rodríguez Montiel (2018a). 
3 Dentro de los estudios sobre literatura y arte latinoamericano, el concepto hubermasiano de anacronismo, inseparable de las nociones de imagen y supervivencia (2002), ha sido decisivo para la inauguración de una amplia y vigente línea de investigación centrada en una multiplicidad de problemas y debates en torno al tiempo y la contemporaneidad. Menciono, a título ilustrativo, algunas producciones: Susana Scramim; Raúl Antelo (2007, 2012), Florencia Garramuño (2009, 2015); Julio Premat (2013, 2014, 2016) y Graciela Speranza (2017).

4 Sobre el poder de lo inactual como fuerza constitutiva de lo literario ver: Giordano.

$5 \mathrm{El}$ problema de la contemporaneidad es, desde hace poco más de cuatro décadas, una de las preocupaciones centrales del campo de la teoría y la crítica a escala global. Su estudio ha arrojado hasta la fecha múltiples y contrapuestas vías de comprensión y análisis. Ejemplo de ello son las categorías de pretéritos presentes de Andreas Huyssen, presentismo de François Hartog, tiempo cero de Josefina Ludmer, aceleracionismo de Nick Srnicek y Alex Williams y postcontemporary de Armen Avanessian y Suhail Malik. La noción anacrónica de contemporaneidad se presenta, de este modo, como una conceptualización más dentro de un conjunto de elaboraciones teóricas heterogéneas en torno a un mismo problema. Cabe destacar, asimismo, dentro de los estudios de la literatura y el arte latinoamericano, el trabajo colectivo editado por Érica Durante en torno a las diferentes temporalidades figuradas en la literatura latinoamericana contemporánea.

6 Para una lectura crítica sobre las nuevas formas errantes de la literatura latinoamericana contemporánea, véase especialmente: Speranza (2012).

7 Para una focalización en la noción de "pérdida» como eje problemático de la narrativa paulsiana, ver: Rodríguez Montiel (2015).

$8 \mathrm{El}$ devenir-monstruo del yo que se pronuncia en Wasabi es, en efecto, la estrategia literaria a la que Pauls apela para transponer lo autobiográfico en la novela. Pauls efectivamente es invitado a pasar dos meses en Saint-Nazaire a cambio de que escriba «unas veinte o veinticinco páginas, cuyo único requisito era que mantuviera alguna relación, sin especificar cual, con el lugar» (Tizón:3). El autor, ya en Buenos Aires, redobla el desafío y escribe una novela que incorpora «en exceso» (3) elementos autobiográficos a la ficción. El nombre real de su esposa de entonces (Viviana Tellas), el nombre de su editor francés (Bouthemy) y el acaecer de una alteración en el cuerpo («Yo efectivamente, tenía un pequeño quiste en la base de la nuca y había hecho, sin resultados, algunas incursiones por la homeopatía, para salvarme de la cirugía» -3-), son ejemplo de ello.

9 Para una profundización en la figura de «impostura» en la escritura paulsiana ver: Rodríguez Montiel (2018b).

10 Cito: «Todos, absolutamente todos, como si se hubieran puesto de acuerdo en un cónclave secreto, pasaron a llamarlo con el nombre que figuraba en su credencial, salvoconducto al que no podía siquiera pensar en renunciar (...): "Idelber esto", "Idelber aquello", abuso flagrante que los participantes brasileños, de paso, aprovecharon para hablarle directamente en portugués, como si ese insignificante rectángulo plastificado bastara para nacionalizarlo (2003:243)».

11 Cito: «La pregunta es si logró engañar a sus anfitriones (...) Jamás le hicieron sentir que sospecharan nada (...) Una tarde (...) aprovechó un recodo particularmente incómodo de la conversación (...) para contar su debut como DJ, dos años atrás, en un pequeño club nocturno de Buenos Aires. Lo contó con una emoción mal reprimida, entrecortando unas torpes frases de asmático, como si (...) temiera que alguna de las personas de la mesa leyera entre líneas la verdad entera y lo reconociera como lo que era: un estafador (2013:3-4).

12 Para un desarrollo centrado en la relación entre Marcel Proust y Alan Pauls en El pasado, ver: Rodríguez Montiel (2017).

13 Se constata, a su vez, en el fragmento final de La vida descalzo - escena de iniciación lectora sobre la que orbita fantasmáticamente una cita de «Sur la lecture» de Proust-, otro pasaje de la literatura paulsiana en la que se afirma el binomio lectura/felicidad: «En la escena hay un chico. Tiene diez u once años. Está de vacaciones en la playa, un lugar que asocia con la forma más perfecta de la felicidad (...) Un día se despierta, traga, siente alguna molestia en la garganta. Tiene unas líneas de fiebre. Deciden que se quede en casa. El chico reacciona mal y se amarga: es un día espléndido (...) Se mete en la cama: el fresco de las sábanas recién cambiadas le da escalofríos (...) Piensa en todos los juegos que no jugará, todas las olas que no barrenará, todos los helados que no comerá, todas las veces que no meará en el agua (...) y mientras arrima el vaso de jugo y se acomoda en la cama y abre el libro, se da cuenta casi con escándalo que no está triste, que la oscuridad le gusta (...) y que el libro que acaba de abrir y que ya cierra su trampa sobre él (...) es, como lo demostrarán las cuatro horas ininterrumpidas que pasará con él (...) el otro lugar que tiene la forma de la felicidad perfecta, y que, 
como escribió alguien a quien él leerá recién veinte años más tarde, cuando ya no esté circunstancial sino crónicamente enfermo, tanto que sólo será capaz de hacer lo único que quiere hacer, quemarse los ojos leyendo, quizá no haya habido días en nuestra infancia más plenamente vividos que aquellos que creímos dejar sin vivirlos, aquellos que pasamos con el libro por el que más tarde, una vez que lo hayamos olvidado, estaremos dispuestos a sacrificarlo todo (2006:123-125)».

14 Para una profundización del estatuto a contratiempo de la literatura paulsiana ver: Rodríguez Montiel (2018a).

\section{Bibliografía}

Agamben, G. (2008). ¿Qué es lo contemporáneo? En Desnudez. Buenos Aires: Adriana Hidalgo, 2014, 17-29.

Antelo, R. (2007). Tempos de Babel: anacronismo e destruição. São Paulo: Lumme editor. (2012). El tiempo, someterlo, suspenderlo. Pós: Belo Horizonte, (2), 176-191.

Avanessian, A. y Malik, S. (2016) The Time-Complex. Postcontemporary». Dis Magazine. http://dismagazine. com/discussion/81924/the-time-complex-postcontemporary/

Avaro, N. (2016). La frase (Alan Pauls). En La enumeración: narradores, poetas, diaristas y autobiógrafos. Rosario: Nube Negra, 147-155.

Barthes, R. (2002). Cómo vivir juntos. Simulaciones novelescas de algunos espacios cotidianos. Buenos Aires: Siglo XXI, 2003.

Benjamin, W. (1989 [1940]). Tesis de filosofía de la historia. En Discursos interrumpidos I. Filosofía del arte de la historia. Buenos Aires: Taurus, 176-191.

Didi-Huberman, G. (2000). Ante el tiempo. Historia del arte y anacronismo de las imágenes. Buenos Aires: Adriana Hidalgo, 2011.

(2002). La imagen superviviente. Historia del arte y tiempo de los fantasmas en Aby Warburg. Madrid: Abada Editores, 2009.

Dosse, F. (2012). Del uso razonado del anacronismo. En El giro reflexivo de la historia. Recorridos epistemológicos y la atención a las singularidades. Santiago de Chile: Universidad Finis Terrae, 43-72.

Durante, É. (Ed.) (2015). Los meridianos de la globalización. Ensayos sobre el tiempo en la literatura latinoamericana contemporánea. Louvain-la-Neuve: Presses universitaires de Louvain. E-book.

Febvre, L. (1947). El problema de la incredulidad en el siglo XVI. La religión de Rabelais. Madrid: Akal, 1993.

Garramuño, F. (2009). La experiencia opaca. Literatura y desencanto. Buenos Aires: Fondo de Cultura Económica.

(2015). Mundos en común. Ensayos sobre la inespecificidad en el arte. Buenos Aires: Fondo de Cultura Económica.

Giordano, A. (2017). ¿A dónde va la literatura? La contemporaneidad de una institución anacrónica. El taco en la brea, (4), 133-146.

Hartog, F. (2003). Regímenes de historicidad. Presentismo y experiencias del tiempo. México: Universidad Iberoamericana, 2007.

Huyssen, A. (2001). En busca del futuro perdido. Cultura y memoria en tiempos de globalización. Buenos Aires: Fondo de Cultura Económica, 2007.

Laera, A. (2014). Ficciones sobre el dinero. Argentina 1890-2001. Buenos Aires: Fondo de Cultura Económica.

Ludmer, J. (2010). Aquí América latina: Una especulación. Buenos Aires: Eterna Cadencia.

Loraux, N. (1992). Elogio do anacronismo. En Tempo e Historia. São Paulo: Companhia das Letras. Secretaría Municipal de Cultura, 57-70. 
Nietzsche, F. (1874). Consideraciones Intempestivas 1873-1876. Buenos Aires: Alianza Editorial, 2002.

Pauls, A. (1994). Wasabi. Barcelona: Anagrama, 2012.

(2003). El pasado. Barcelona: Anagrama.

(2006). La vida descalzo. Buenos Aires: Sudamericana.

- (2013). Noche de Opwijk. https://www.pagina12.com.ar/diario/verano12/

subnotas/23-62267-2013-02-03.html

(2018). Trance. Buenos Aires: Ampersand.

Premat, J. (2013). Los relatos de la vanguardia o el retorno de lo nuevo. Cuadernos de literatura, (37), 47-64.

- (2014). Contratiempos. Literatura y época. Revista de Estudios Hispánicos, (48), 1-17.

(2016). Fin de los tiempos. Comienzo de la literatura. Eidos, (24), 104-123.

Rancière, J. (1996). Le concept d' anachronisme et la vérité de l'historien. L'Inactuel, (6), 53-68.

Rodríguez Montiel, E. (2015). La "pérdida» como circuito literario. Notas sobre la obra (1994-2013) de Alan

Pauls. En Gerbaudo, A. (Comp.), II Coloquio de Avances de Investigaciones del CEDINTEL. Santa Fe: UNL. E-book.

(2017). Autonomía y nostalgia: Marcel Proust en El pasado de Alan Pauls. En Echague, H. (Ed.), El

texto como reflexividad. Crítica y teoría en la literatura. Santa Fe: UNL, 147-160.

(2018a). La literatura como jet lag. Anacronismo y contemporaneidad en Alan Pauls. CELEHIS,

(35), 179-193.

(2018b). Infancia e impostura en La vida Descalzo de Alan Pauls. Badebec, (14), 54-66.

Scramim, S. (2007). Literatura do presente. História e anacronismo dos textos. Chapecó: Argos.

Siskind, M. (2016). Deseos cosmopolitas. Modernidad global y literatura mundial en América Latina. Buenos Aires: Fondo de Cultura Económica.

(2018). Towards a cosmopolitanism of loss: an essay about the end of the world. (Capítulo de libro manuscrito inédito). Harvard University.

Speranza, G. (2012). Atlas portátil de América Latina. Arte y ficciones errantes. Buenos Aires: Anagrama.

(2017). Cronografias. Artey ficciones de un tiempo sin tiempo. Barcelona: Anagrama.

Srnicek, N. y Williams, A. (2013). Acelera. Manifiesto por una política aceleracionista. Comité Disperso. https:// comitedisperso.wordpress.com/2013/07/30/manifiestoaceleracionista1/

Tizón, H., Martini, J. C. y Pauls, A. (1995). Experiencia y lenguaje I. Punto de Vista, (23), 1-4. 